\title{
MORPHOMETRIC STUDY OF INGUINAL CANAL ON CADAVER
}

\section{Vipin Kumar *1, Jignesh Patel ${ }^{2}$, Chakraprabha Sharma ${ }^{3}$, Suman Inkhiya ${ }^{4}$.}

*1 Associate Professor Department of Anatomy American International Institute of Medical Sciences, Udaipur Rajasthan, India.

${ }^{2}$ Assistant Professor Department of Anatomy, American International Institute of Medical Sciences, Udaipur Rajasthan, India.

${ }^{3}$ Tutor, Department of Anatomy, American International Institute of Medical Sciences, Udaipur Rajasthan, India.

${ }^{4}$ Tutor, Department of Anatomy American International Institute of Medical Sciences, Udaipur Rajasthan, India.

\section{ABSTRACT}

Background: The inguinal canal is an oblique intermuscular passage lying above the medial half of the inguinal ligament. Its size and form vary with age and sex, although it is present in both sexes, it is most well developed in male. The inguinal canal in both sexes has been studied by many workers both in India and in other countries. It is observed that the inguinal hernia and recurrence of hernia after surgery is very common in the kosi region of Bihar. This observational study may help the surgeons during the operation of inguinal hernia.

Materials and Methods: Present study conducted at the department of Anatomy, Katihar medical college and hospital Katihar and Lord Buddha Kosi Medical College, Saharsa during the period of 2010 to 2016. The cadaver provided for dissection to the student of first professional MBBS, are selected for the study. Cadavers with injured groin region are not taken for the study. Measurements were done by stainless steel scale and spreading calliper during dissection of groin region.

Results: Anatomy of inguinal canal, superficial inguinal ring, the deep inguinal ring and the related structures was studied in details in 50 cadavers in the dissection hall at the time of dissection. During this study I have found that the average length of inguinal canal in the male was $38.35 \mathrm{~mm}$. The longest diameter of deep inguinal ring is $13 \mathrm{~mm}$ and smallest diameter is $9 \mathrm{~mm}$. The average measurement of superficial inguinal ring was $12 \mathrm{~mm}$ along the base and $24 \mathrm{~mm}$ from apex to base.

Conclusion: At the end of the study I have found a little variation from the established facts related to diameter of superficial inguinal ring, position of deep inguinal ring and direction of fibres of external oblique aponeurosis.

KEY WORDS: Inguinal Canal, Deep Inguinal ring, Superficial Inguinal ring, Stainless steel scale and Spreading calliper.

Address for Correspondence: Dr. Vipin kumar, Associate Professor Department of Anatomy American International Institute of Medical Sciences, Udaipur Rajasthan, India. Mobile No. 9006879454 E-Mail: drvipinkumarjha@gmail.com

Access this Article online

Quick Response code

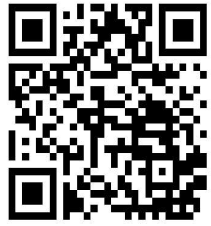

DOI: $10.16965 /$ ijar.2018.147
Journal Information

International Journal of Anatomy and Research

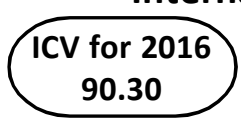
ISSN (E) 2321-4287 | ISSN (P) 2321-8967 https://www.ijmhr.org/ijar.htm DOI-Prefix: https://dx.doi.org/10.16965/ijar

\section{Article Information}

Received: 15 Feb 2018

Peer Review: 15 Feb 2018

Revised: None
Accepted: 07 Mar 2018

Published (O): 05 Apr 2018

Published (P): 05 Apr 2018

\section{INTRODUCTION}

Inguinal canal is the natural hiatus in the tissue of the anterior abdominal wall and is formed from various layers of the wall in the region of 
groin [1]. The word inguinal derived from the Latin word inguen means the growin. Till the year 1750 , nothing more was known about the anatomy of inguinal region. The great contribution of the surgical anatomy was between the years 1750 to 1865 , as was called the age of dissection [2]. The anatomy of inguinal canal was studied by men, whose names are still associated with structures in that area - Veseins, Scarpa, Cooper, Gimbernate and Hesselbach.

By the time the knowledge about the inguinal region and its canal is increasing gradually. Now we know so many things about inguinal region. The inguinal canal is about $4 \mathrm{~cm}(40 \mathrm{~mm})$ and lying above the medial half of the inguinal ligament [3]. It extends from the deep inguinal ring to the superficial inguinal rings: the length depends on the age of the individual, but in the adult is between 30 to $40 \mathrm{~mm}$ long. The canal is bounded anteriorly by the skin, superficial fascia and aponeurosis of external oblique. In its lateral one-third, the anterior wall is reinforced by the muscular fibres of the internal oblique just above their origin from the inguinal ligament. Posteriorly lies the reflected inguinal ligament, the conjoint tendon and the transversalis fascia, which separate it from extra peritoneal connective tissue and peritoneum. Superiorly lies the arched fibres of internal oblique and transversus abdominis, forming the conjoint tendon, and inferiorly is the union of the transversalis fascia with the inguinal ligament and, at the medial end, the lacunar ligament. The upper end of the inguinal canal is the deep inguinal ring, which is the normal opening in the transversalis fascia. It lies midway between the anterior superior iliac spine (ASIS) and the symphysis pubis (Mid inguinal point) approximately $12.5 \mathrm{~mm}(1.25 \mathrm{~cm})$ above the inguinal ligament [1]. The superficial inguinal rings is a triangular gap in the aponeurosis of external oblique and lies above and lateral to the pubic crest. The pubic crest forms the base of the triangle. The sides of the triangle are called crura, which meet laterally to form an obtuse apex. It is about $25 \mathrm{~mm}(2.5 \mathrm{~cm}$.) long and $12 \mathrm{~mm}$. (1.2 cm.) broad at the base [3].

\section{MATERIALS AND METHODS}

The study was done in the Katihar medical college and hospital Katihar and Lord Buddha
Kosi Medical College, Saharsa during the period of 2010 to 2016 . The cadaver provided for dissection to the student of first professional MBBS, are selected for the study. Cadavers with injured groin region are not taken for the study. Measurements were done by stainless steel scale and spreading calliper during dissection of groin region. During dissection we follow the steps of dissection according to Cunningham's manual of practical anatomy vol. 2, $15^{\text {th }}$ edition. Measurements taken for this study are length of inguinal canal, diameter of deep inguinal ring and diameter of superficial inguinal ring and closely observe the superficial fascia, external oblique muscle and their aponeurosis, transversus abdominis and fascia transversalis.

Surface landmarks were taken before the start of the dissection by marking the anterior superior iliac spine (ASIS), pubic symphysis (PS) and pubic Tubercle (PT) and taking the length of inguinal ligament. The distance between the ASIS and superficial inguinal ring as well as the distance between the ASIS and deep inguinal ring were taken after exposing the external oblique and opening the inguinal canal respectively; after the incision was made and the superficial inguinal ring was identified, the distance between the ASIS and the lateral edge of deep inguinal ring, was taken in millimetre. The distance between the ASIS and deep inguinal ring, was taken after the inguinal canal was opened. The cord dissected and the sac transacted and pulled perpendicular to the abdominal wall at the internal ring. This distance (ASIS to deep inguinal ring) subtracted from the previous one (ASIS to superficial inguinal ring) represent the length of inguinal canal. The measurement was taken by the help of spreading calliper, from the most prominent palpable point of ASIS to the midpoint of deep inguinal ring and midpoint of superficial inguinal ring. The diameter of superficial inguinal ring and deep inguinal ring were taken with the help of spreading calliper and recorded. All the measurement was taken in millimetre.

\section{RESULT AND DISCUSSION}

Till the year 1750, nothing more was known about the anatomy of inguinal region. The great contribution of the surgical anatomy was between the years 1750 to 1865 , as was called 
the age of dissection [2]. The study showed that in the individuals without inguinal hernias the deep inguinal ring did not correspond to the mid inguinal ligament or mid inguinal point, but rather to an area between these two landmarks. The surface marking of the deep inguinal ring may be best described as at the mid -inguinal region [3].

Sanjay P. et al defined the position of the deep ring in patients undergoing elective inguinal hernia repair. Thirty consecutive male patients undergoing indirect inguinal hernia repair under local anaesthesia were studied. The following landmarks were marked on the patient with a felt pen: ASIS, femoral arty, deep inguinal ring, pubic tubercle (PT), and pubic symphysis (PS). The distance of each point from the ASIS was measured in centimetres. The relation of femoral artery to the deep inguinal ring was confirmed by palpating through the deep ring during surgery. The femoral artery was consistently identified midway between the ASIS and PS (mid-inguinal point). The mean distance from ASIS to the deep ring and femoral artery were 8.8 and $7.7 \mathrm{~cm}$ respectively. Contrary to standard teaching, this study demonstrates that the deep inguinal ring lies medial, not lateral, to the femoral artery. This may clarify some of the variations in textbook of anatomy and explain the difficulty in distinguishing direct and indirect inguinal hernias pre-operatively [4].

In present study anatomy of inguinal canal, superficial inguinal ring, deep inguinal ring, external oblique aponeurosis, transversus abdominis and fascia transversalis are very closely observed during the dissection of the anterior abdominal wall and groin. During this observational study my findings are as follows:

Superficial fascia: There are two layers in the superficial fascia of the inguinal region in all the cases. One is superficial fatty layer, the fascia of camper and the other is deep membranous layer the fascia of scarpa.

The superficial fascia contained varying amount of fat. In females the amount of fat was comparatively more than in males. The line joining the two ASIS is the landmark, where the fascia splits in two layers. The superficial fatty layer is devoid of fat over the penis. In the scrotum it is replaced by dartos muscle.
The deep membranous layer crosses the inguinal ligament and gets attached to the fascia lata of the thigh.

These findings are similar with the description in the text book of anatomy $[1,4]$.

External oblique aponeurosis: The external oblique is completely aponeurotic in the inguinal region [5].The general direction of the fibres of the external oblique aponeurosis is downward and medially $[5,6]$.

In this study on cadavers the direction of fibres was downward and medially in $90 \%$ and was relatively horizontal in the remaining $10 \%$.

Superficial Inguinal Ring: The superficial inguinal ring is roughly triangular in shape [6]. The diameter of superficial inguinal ring is $2.5 \mathrm{~cm}$ long and $1.2 \mathrm{~cm}$ broad at the base. In female it was smaller [3].

According to my observation on cadaveric dissection the average measurement was found to be $12 \mathrm{~mm}$ along the base and $24 \mathrm{~mm}$ from apex to base.

Deep inguinal ring: Deep inguinal ring is oval in shape when viewed from in front. Its shape is varies in different subject and much larger in the males than the females [6]. It was situated in the transversalis fascia midway between the ASIS and PS and $1 / 2$ inch above the inguinal ligament [4]. Deep inguinal ring is midway between ASIS and PS and about $1 \mathrm{~cm}$ above the inguinal ligament [1].The shape of the ring was oval. The long axis laid in an oblique direction when seen from infront during dissection. Its size varies between adults and larger in males.

My observation during the dissection, the deep inguinal ring was an oval opening in the fascia transversals, $12.7 \mathrm{~mm}$ above the mid inguinal point. The long axis of the oval shape was almost vertical in all the cases. It was slit like in $60 \%$. In $30 \%$ it could admit the tip of the little finger. In $10 \%$ it was larger and could barely admit the tip of the fore finger. In $10 \%$ female specimens it was slit like and very small.

Inguinal canal: The length of inguinal canal varied from $36 \mathrm{~mm}$ to $40.7 \mathrm{~mm}$. The average length of inguinal canal was $38.35 \mathrm{~mm}$. The length of inguinal canal in case of female cadaver was about 2 to $3 \mathrm{~mm}$ less than that in the case of male. 
Cremaster: The cremaster muscle was poorly developed in the present study and only a few loops could be identified.

\section{CONCLUSION}

The anatomy of inguinal canal was studied on 50 cadavers out of which 45 were male and 5 were female.

The inguinal canal was dissected stepwise beginning from the skin. The relation of inguinal canal was studied and the measurements of the inguinal canal, superficial inguinal ring, deep inguinal ring, distance between ASIS and superficial inguinal ring, and deep inguinal ring were recorded.

The length of inguinal canal varied from $36 \mathrm{~mm}$ to the $40.7 \mathrm{~mm}$. The average length of inguinal canal was $38.35 \mathrm{~mm}$. The length of inguinal canal in case of females was about 2 to $3 \mathrm{~mm}$ less than that in the case of males.

In most of the cases, the anterior wall of the canal strengthened by the muscular fibres of the internal oblique opposite the point where the deep inguinal ring is situated.

Musculo-aponeurotic fibres of transverses abdominis did not take part in the formation of anterior wall.

In posterior wall, fascia transversalis was found to be thicker in the inguinal region. The conjoint tendon formed the posterior wall in the medial half in almost all the cases and in a significant number of cases, muscular fibres were also present in it. The reflected part of the inguinal ligament formed the posterior wall in $50 \%$ of the cases.
The posterior wall was found to be strengthened by conjoint tendon and the reflected ligament just opposite the superficial inguinal ring.

The superficial inguinal ring was found to be triangular in all cases. Its measurements in the females were found to be smaller. The two crura of the ring were aponeurotic and the internal fibres were less defined in cases of females.

The deep inguinal ring was found to be an oval opening in the fascia transversalis and is about $12.7 \mathrm{~mm}$ above the mid inguinal point. In the female, it was slit like and smaller than males in diameter.

\section{Conflicts of Interests: None}

\section{REFERENCES}

[1]. Standring S, Borley NR, Collins P, Crossman AR, Gatzoulis MA, Healy JC, et al. Gray's Anatomy: The Anatomical Basis of Clinical Practice $41^{\text {st }}$ ed. Vol.1998. London: Elsevier, Churchil Livingstone. 2016; 1068p.

[2]. Akita K, Niga S et al: Anatomic basis of chronic groin pain with special reference to sports hernia. Surg Radiol Anat. 1999;21(1):1-5.

[3]. Singh V Text book of Anatomy vol 2. $2^{\text {nd }}$ ed. New Delhi: Elsevir, RELX India Private Limited; 2015-2016. 49p.

[4]. Sanjay P, Reid TD Bowrey DJ, Woodward A: Defining the position of deep inguinal ring in patients with indirect inguinal hernias. Surg Radio Anat. 2006 May;28(2):121-4. Epub 2006 Apr 11.

[5]. Peri G, Farina F, et al: Clinical and anatomic features of the inguinal canal during hernia. Ital $\mathrm{j}$ Anat Embryol. 1996 Apr-jun;101(2):69-80.

[6]. Koliyadan SV, Narayan G, Balasekran P: Surface marking of the deep inguinal ring. Clin Anat. 2004 Oct;17(7):554-7.

How to cite this article:

Vipin Kumar, Jignesh Patel, Chakraprabha Sharma, Suman Inkhiya. MORPHOMETRIC STUDY OF INGUINAL CANAL ON CADAVER. Int J Anat Res 2018;6(2.1):5172-5175. DOI: 10.16965/ijar.2018.147 